\title{
PA-130 MODIFIABLE RISK FACTORS OF BURULI ULCER IN COMMUNITIES OF TWO ENDEMIC LOCAL GOVERNMENT AREAS OF OGUN STATE, NIGERIA
}

Olaoluwa Akinwale, Adeniyi Adeneye, Sylvanus Ezeugwu, Yetunde Olukosi, Babatunde Adewale, Medinat Sulyman, Margaret Mafe, Jane Okwuzu, Pam Gyang, Timothy Nwafor, Uzoma Henry, Bilkisu Musa, Innocent Ujah. NIMR, Nigeria

10.1136/bmjgh-2016-000260.157

Background Buruli ulcer (BU) remains a neglected tropical disease globally including in Nigeria despite its severe health and socio-economic consequences. This study was conducted as there is a paucity of data on community knowledge and risk factors of BU in Nigeria.

Methods The study was conducted in the BU-endemic Yewa North and Yewa South local government areas (LGAs) of Ogun State, Nigeria. Study population included community members selected using multi-stage sampling techniques. Household survey using a semi-structured questionnaire was used for data collection. Data were analysed using SPSS (version 20) software. Results A total of 236 consented respondents were interviewed (Yewa North 76.7\% vs Yewa South 23.3\%; males $48.7 \%$ vs females $51.3 \%$ ) with an average age of 33.1 years. Only $39.0 \%$ had a minimum of secondary education. A little over half (128; $54.2 \%$ ) reported having knowledge of BU in their communities. However, only $35.6 \%$ adjudged $\mathrm{BU}$ a common disease in their communities while $56.0 \%$ perceived it as a serious health challenge. Few (14.0\%) respondents had an average of one household member who had or have BU. Most (64.8\%) did not know the cause of BU while $9.7 \%$ attributed it to witchcraft/Olobutu, bacteria (4.2\%), water contact $(3.0 \%)$ and poor hygiene $(3.0 \%)$. $53.4 \%$ visit riverbanks for activities that were predominantly: washing (37.3\%); swimming (35.7\%); fetching water (19.8\%); and agricultural activities (4.0\%). Gender and age had no significant influence on respondents' knowledge of the cause of BU $(p>0.05)$. Swimming and other activities on the riverbanks associated with BU had significant correlation with report of BU cases in the household $(\mathrm{p}<0.05)$.

Conclusions Pervasive knowledge of BU cases and highperceived seriousness of the disease in the study communities exist. Nonetheless, there is need for more public health education emphasising common modifiable risk factors and actual cause of BU. Overall, these results provide insights for BU programme planning and optimisation. 